cases originally anticipated (Department of Health, 1993). Professional opinion on whether further legislation to compel acceptance of community treatment is necessary remains divided (Burns, 1999; Moncrieff \& Smyth, 1999). If future legislation lacks credibility with clinicians, it may not be widely used.

\section{Acknowledgements}

We are grateful to the CRMOs who completed questionnaires and to the Mental Health Act administrators who responded to the enumeration surveys and identified patients. This work was undertaken by the Institute of Psychiatry, which received funding from the Department of Health. The views expressed are those of the authors and not necessarily those of the Department of Health.

\section{References}

BURNS, T. (1999) Invited commentary: community treatment orders. Psychiatric Bulletin, 23, 647-648.
DAVIES, S., BRUCE, J. \& FALLOWS, S. (1999) Section 25 Aftercare under supervision: the first eighteen months' Law, 39, 214-218.

DEPARTMENT OF HEALTH (1993) Legal Powers on the Care of Mentally III People in the Community. Report of the Internal Review. London: Department of Health.

- (1999) Reform of the Mental Health Act 1983: Proposals for Consultation. Cm 4480. London: Stationery Office.

EASTMAN, N. (1995) Anti-therapeutic community mental health law. British Medical Journal, 310, 1081-1082.

KNIGHT, A., MUMFORD, D. \& NICHOL, B. (1998) Supervised discharge order: the first year in the South and West Region. Psychiatric Bulletin, 22, 418 420

MAYS, N. \& POPE, C. (1995) Rigour and qualitative research. British Medical Journal, 311, 109-112. experience. Medicine, Science and the
MONCRIEFF, J. \& SMYTH, M. (1999) Community treatment orders: a bridge too far? Psychiatric Bulletin, 23, 644646.

PINFOLD,V., BINDMAN, J., FRIEDLI, K., et al (1999) Supervised discharge orders in England: compulsory care in the community. Psychiatric Bulletin, 23 199-203

TRAUER, T. \& SACKS, T. (1998) Medication compliance: a comparison of the views of severely mentally ill clients in the community, their doctors and their case managers. Journal of Mental Health, 7, 621-629.

WEBER, R. P (1985) Basic Content Analysis: Quantitative Applications in the Social Sciences (no. 49). London: Sage Publications.
*Donna Franklin Research Worker, Department of Clinical Psychology, University of Leeds, 15 HydeTerrace, Leeds LS2 9JT, Vanessa Pinfold Project Coordinator, Jonathan Bindman Clinical Lecturer, Graham Thornicroft Professor of Community Psychiatry, Institute of Psychiatry, De Crespigny Park, London SE5 8AF; tel. : 0207848 0714; fax: 02072771462

Psychiatric Bulletin (2000), 24,415-417

\title{
Off-label prescribing by psychiatrists
}

A questionnaire was sent to 200 psychiatrists asking them about their off-label prescribing in the preceding month. One hundred and sixteen replies $(58 \%)$ were obtained. Seventy- $\operatorname{six}(65 \%)$ respondents had prescribed medication off-label within the past month. Only 5 (4\%) had ever received a complaint from patients related to their off-label prescribing. If this region is typical, off-label prescribing is common amongst psychiatrists. No formal guidelines exist except for the use of high dose neuroleptics. A suggested guideline is given in this article.
Many psychiatrists think that off-label prescribing is occasionally necessary when attempting to treat the very ill or treatment-resistant patient. However, the prevalence of this practice among psychiatrists is not known. In their summary of the development of product licences, Healy and Nutt (1998) perceived need for licences to state the indications for their drugs and also for the pharmaceutical companies to provide proof of efficacy for stated indications. They also describe the barriers to obtaining a product licence: these include the need for the company to make an economic return balanced against the high cost of clinical trials. Some clinical trials are very difficult to perform (eg. for the prophylaxis of bipolar disorder), or raise particular ethical difficulties (such as entering children or people with learning disabilities into studies). The authors concluded that use of off-label medication was a "necessary part of the art of medicine".

The use of off-label prescriptions has particularly exercised child and adolescent psychiatrists (since relatively few psychotropic drugs are licensed for use in children) and psychiatrists dealing with those with a learning disability (British Association for Psychopharmacology, 1997; Vitello \& Jensen, 1997). A recently published study (Conroy et al, 2000) looked prospectively at off-label prescribing in five paediatric wards in five countries over a period of 4 weeks. In that study the term off-label prescribing included: changed frequency of prescribing, a different route of administration, modification of licensed drugs and prescribing important drugs. During the period of the study $67 \%$ of children were prescribed drugs offlabel and $46 \%$ of all drug prescriptions were off-label.

Our survey was designed to see how common offlabel prescribing is among psychiatrists and to ascertain whether it is felt that there are insufficient guidelines for this aspect of prescribing.

\section{Method}

All senior psychiatrists (consultants, specialist registrars and non-career grades) working in the Wessex region were surveyed using a postal questionnaire. This was sent 
to each doctor twice, and an addressed return envelope was enclosed.

The questionnaire was anonymous, but sought brief original papers details about the doctor's grade and speciality. It then asked questions in turn about each of the following three types of off-label prescribing:

(a) prescribing for a drug outside its produce licence indication; an example would be the use of sodium valproate as a mood stabiliser (in the UK);

(b) prescribing a drug above the maximum dose given in the data sheet;

(c) prescribing a drug to a patient outside the recommended age range; an example would be the prescription of many of the new antidepressants in children.

The psychiatrist was asked if he or she had prescribed any drug off-label in the past month and to list any such drugs and their indications (or dosages, or age range, as appropriate). Questions were then asked about the legal status of the patients, whether the doctor had any worries about this aspect of prescribing and if they felt sufficient guidelines existed. The final section asked if the doctor had received any complaints from patients about their off-label prescribing; and also left space for comments. The name, use or dose of each drug given was checked with the ABPI Compendium of Data Sheets and Summaries of Product Characteristics 1999--2000 (Association of the British Pharmaceutical Industry, 1999).

For ease of analysing results and to ensure anonymity all psychiatrists working predominantly with adults under the age of 65 years (eg. forensic psychiatrists, substance misuse specialists and psychotherapists) were included under the term 'adult psychiatrists'. For similar reasons all non-career-grade doctors were included under a single grade. All percentages quoted were rounded to the nearest whole figure.

\section{Results}

The response rate was $58 \%$. Of the 116 who responded to the questionnaire, 65 (56\%) were consultants, 33 (29\%) were specialist registrars and 17 (15\%) were noncareer grades; the response to grade was missing in one case. Thirteen (11\%) respondents were working in child and adolescent psychiatry, $29(25 \%)$ in old age psychiatry and $73(63 \%)$ in adult specialities; again, 1 response was missing.

A total of $76(65 \%)$ of the 116 respondents had prescribed drugs off-label in at least one of the three ways listed in the preceding month (Table 1).

Prescribing out of the product licence indication was carried out predominantly by adult and old age psychiatrists. As expected, there was little prescribing of drugs above the maximum recommended dosage.

Very few psychiatrists $(n=5,4 \%)$ had received complaints about their prescription of drugs off-label, but it was clear from comments that possible medico-legal problems were of concern to some respondents.

It was not possible to quantify the use of particular drugs, as the number of named drugs was often less than the total number of drugs given. This is probably because a particular drug was prescribed on more than one occasion. Examples of the drugs given included sodium valproate for bipolar disorder, olanzapine for psychoses other than schizophrenia, atypical antipsychotics for agitated dementia, reboxetine to the elderly and newer antidepressants to children.

There were insufficient replies to analyse the lega status of the patients given off-label drugs. However,

Table 1. Use of drugs off-label in past month

\begin{tabular}{|c|c|c|c|c|}
\hline & Outside indication & Above BNF dose & Outside age range & Any use off-label \\
\hline Yes & $57(49 \%)$ & $22(19 \%)$ & $14(12 \%)$ & $76(65 \%)$ \\
\hline Missing & $0 \quad(0 \%)$ & $0 \quad(0 \%)$ & $1(1 \%)$ & - \\
\hline Mean no. drugs per psychiatrist $(n=116)$ & 2.4 & 0.4 & 0.4 & \\
\hline Maximum no. prescribed & 30 & 12 & 13 & \\
\hline
\end{tabular}

1. For this calculation missing values were counted as 'no' use of drugs off-label in that category.

Table 2. Examples of licensed indications for specific drugs (British Medical Association, 1999)

\begin{tabular}{|c|c|c|c|c|c|}
\hline Haloperidol & Olanzapine & Risperidone & Amitriptyline & Fluoxetine & Paroxetine \\
\hline $\begin{array}{l}\text { Schizophrenia and other } \\
\text { psychoses } \\
\text { Mania } \\
\text { Psychomotor agitation } \\
\text { Excitement, violent or } \\
\text { dangerously impulsive } \\
\text { behaviour } \\
\text { Severe anxiety } \\
\text { Intractable hiccup } \\
\text { Nausea and vomiting }\end{array}$ & Schizophrenia & $\begin{array}{c}\text { Acute and chronic } \\
\text { psychoses }\end{array}$ & $\begin{array}{l}\text { Depressive illness } \\
\text { Nocturnal enuresis } \\
\text { in children }\end{array}$ & $\begin{array}{l}\text { Depressive illness } \\
\text { Bulimia nervosa } \\
\text { Obsessive--compulsive } \\
\quad \text { disorder }\end{array}$ & $\begin{array}{l}\text { Depressive disorder } \\
\text { Obsessive--compulsive } \\
\text { disorder } \\
\text { Panic disorder } \\
\text { Social phobia }\end{array}$ \\
\hline
\end{tabular}


1. Check that all drugs with a product licence have had a proper therapeutic trial or have been excluded for sound reasons

2. If you are not sufficiently expert in this field obtain a second opinion

3. Familiarise yourself with the evidence surrounding the proposed drug, including drug interactions and side-effects

4. Perform risk-benefit analysis of the proposed treatment. Document this fully

5. Give the patient a full explanation, including the information that the drug will be used outside its product licence. Document the explanation given

6. If full consent is obtained, then begin a cautious trial of the drug, within available dosing schedules. Document the patient's consent

7. Monitor the patient closely. Continue full documentation

8. If the drug is unsuccessful, withdraw it gradually. Document the reason for withdrawal

9. Consider writing up and publishing the case, to add to the knowledge available about the drug and its use

responses indicated that the majority of patients were not detained under a section of the Mental Health Act, and of those who were, not all were able to consent.

\section{Discussion}

The indications for drugs vary widely, even within the same class of compounds, and it is impractical for a practising psychiatrist to memorise them all for each drug. Examples of the variety of indications for seemingly similar drugs are given in Table 2. Owing to these variations it is possible that psychiatrists missed some reporting of their use of drugs off-label. Drugs that psychiatrists mistakenly thought that they had used off-label when in fact they had not were excluded from analysis.

As this is a retrospective survey, it is possible that psychiatrists may have forgotten all the drugs they had prescribed in the past month. It may have been better to have asked them to estimate their use prospectively over a longer period in order to obtain more definitive results, but this was not done as we did not believe it would be realistic for a busy doctor to complete such a task.

The reported use of high-dose neuroleptics may have been lower than the true figure. This is partly because of the effects of p.r.n. (as required) prescribing, which is not always taken into account when calculating neuroleptic dose (Milton et al, 1998). In addition, if a combination of neuroleptics is used at a combined dosage above British National Formulary (British Medical Association, 1999) recommendations, the figure may be even higher. Guidelines to the use of high dose neuroleptics have been published (Thompson, 1994).

The prescription of drugs out of age-range is potentially troublesome for the doctor. It is well known that psychiatrists dealing with children and adolescents may resort to off-label prescribing, as there are often no suitable treatment alternatives. Some drugs are not licensed for use in the elderly (eg. reboxetine) and this also can cause difficulties.

We felt that off-label prescribing is justified in certain circumstances. There is often good evidence for the use of drugs off-label (such as the use of sodium valproate in mania or olanzapine in psychoses other than schizophrenia). The newer antipsychotic drugs tend to be licensed for fewer indications (see Table 2), but they are thought by many to have a more acceptable side-effect profile for the patient. Some respondents cited fear of litigations as a reason for not prescribing drugs off-label, but the Bolam test in medical negligence claims (1957) asks for proof that a body of doctors would act similarly to the doctor in question. This would be easy to prove in many circumstances, for example many anticonvulsants are widely used in the UK and USA as a treatment of bipolar disorder, and many old age psychiatrists use low doses of antipsychotic drugs to reduce agitation in patients with dementia. The more recent Bolitho case (1997) also states that the medical opinion should be capable of withstanding logical analysis. Table 3 shows a suggested guide to prescribing off-label, which might help avoid potential difficulties. Particularly in view of the continuing emphasis on clinical governance and increased accountability, psychiatrists need to be able to defend their actions to both colleagues and patients.

\section{Acknowledgement}

Thank you to Karen Middleton for technical assistance.

\section{References}

ASSOCIATION OF THE BRITISH PHARMACEUTICAL INDUSTRY (1999) ABPI Compendium of Data Sheets and Summaries of Product Characteristics 1999-2000. London: Datapharm Publications Limited.

BRITISH ASSOCIATION FOR PSYCHOPHARMACOLOGY (1997) BAP consensus statement. Child and learning disability

psychopharmacology. Journal of Psychopharmacology, 11, 291-294.

BRITISH MEDICAL ASSOCIATION \& ROYAL PHARMACEUTICAL SOCIETY OF GREAT BRITAIN (1999) British National Formulary. London: Wallingford: BMJ Books. Pharmaceutical Press.

CONROY, S., CHOONARE, I., IMPICCIATORE, P., et al (2000) Survey of unlicensed and off label drug use in paediatric wards in European countries. British Medical Journal, 320, 79-82.

HEALY, D. \& NUTT, D. (1998)

LOWE-PONSFORD, F. L. (1999)

Anticonvulsants in the treatment of bipolar disorder. In Practical Issues in Mood and Anxiety Disorders. No. 8. The Netherlands: SmithKline Beecham.

MILTON, J., LAWTON, J., SMITH, M., etal (1998) Hiddenhigh-dose antipsychotic prescribing: effects of p.r.n. doses. Psychiatric Bulletin, 22, 675-677.

THOMPSON, C. (for the Royal College of Psychiatrists' Panel) (1994) The use of high-dose antipsychotic medication (Consensus statement). British Journal of Psychiatry, 164, 448-458.

VITELLO, B. \& JENSEN, P. S. (1997) Medication development and testing in children and adolescents. Archives of General Psychiatry, 54, 871-876.

Bolam v. Friern Hospital Management Committee [1957] WLR, 582.

Bolitho v. City and Hackney Health Authority [1997] 3WLR, 1151.

Prescriptions, licences and evidence.

Psychiatric Bulletin, 22, 680-684.

*Francesca Lowe-Ponsford Locum Consultant Psychiatrist, BayTree House, Graham Road, Southampton, Hants SO14 OYH， David Baldwin Senior Lecturer and Honorary Consultant Psychiatrist, Southampton University Mental Health Group, Royal South Hampshire Hospital, Brinton's Terrace, Southampton, Hants SO14 OYG original papers 